\title{
Writing with Ev-Words to Transform Science into Action
}

\author{
THOMAS E. BACKER
}

Human Interaction Research Institute, Encino, California

JAMES DEARING AND ARVIND SINGHAL

Ohio University, Athens, Ohio

THOMAS VALENTE

University of Southern California, Los Angeles, California

Centered around his landmark book Diffusion of Innovations, Everett Rogers contributed to the professional literature in a number of fields for more than 40 years. In this article, four of his writing partners briefly examine his impact in the fields of diffusion theory, health communication, and entertainment-education, and in particular his impact on us as writers, as professionals, and as human beings.

This is not an analytic review or a comprehensive summary of the man's body of work. That's been done, including in a prior special issue of the Journal of Health Communication, and will doubtless be done for years to come by scholars and doctoral students. What follows is more a set of personal reflections, with an emphasis on writing that may be particularly appropriate in a journal devoted to health communication, since so much of effective communication begins with the written word.

Ev Rogers wrote a lot -36 books and more than 350 refereed journal articles and book chapters, by one recent count. And he wrote in a very distinctive style, blending crisp statements of science and theory with lively, real-world examples, such as the vivid cases that enliven the pages of Diffusion of Innovations. This tactic reflected one of the basic principles of effective diffusion in his own science-based theory on the subject, that people need to feel information is relevant to their lives, and be motivated emotionally to grasp its significance, in order for science to get transformed into action. Ev also used summaries, lists of principles, and graphical charts to illustrate and bring together the main points he was making in his writing. For those who have either read his works or written with him, this diffusion-oriented writing style helps get the material across persuasively. And this approach has helped shape the writing styles of each of the authors of this article in significant ways.

In effect, Ev's writing style created a kind of "lattice work" in which theory, research, and the real world of practical examples and interventions all are related. The common framework was his fundamental interest in how ideas lead to action.

What's equally remarkable is that his scholarship and influence ranged over such a broad set of topics. Here we talk about the impact of his writing on (a) diffusion of innovations - variously referred to as dissemination, knowledge utilization, and technology transfer; (b) health communication; and (c) a specific subset of health 
communication called entertainment-education. Each of these fields bears the distinctive mark of the written works of Everett Rogers, as well as his lively presence as researcher, teacher, consultant, and professional colleague.

\section{Diffusion of Innovations}

James Dearing, Thomas Valente, and Thomas Backer are long-time researchers and scholars in the diffusion field, with parallel work as consultants and policy advocates on this subject. Each gives his personal view of Ev Roger's impact on the field in the section that follows.

Thomas Backer. When I came into the field of diffusion of innovations in early 1971, as a first-year UCLA clinical psychology graduate student, it was to work on a diffusion-related project at the nonprofit Human Interaction Research Institute (HIRI). Founded in 1961, HIRI had already done pioneering work in this area, drawing upon Ev Rogers's theory and writings to do so. In fact, when I came to HIRI, one of my first reading assignments was Ev's classic book, Diffusion of Innovations, then in its second edition and already one of the most widely cited texts in the social sciences. HIRI's founder Ed Glaser and Ev Rogers had not yet met, but both were among the pioneers of the 1960s in the diffusion field. I was told that Ev's book would help shape my basic understanding of this field, and indeed it did.

My first HIRI project, on which I was a research assistant, involved identifying and cataloguing unpublished psychological tests, so that they could be more widely used in both research and practice, and it was funded by the National Institute of Mental Health. The 1,100 test descriptions that resulted were available through the National Clearinghouse on Mental Health Information, and also were in a thick book for which HIRI continued to receive requests for many years after the book was published in 1973. The format of this knowledge reflected principles set forth in Diffusion of Innovations, and in Ev's own writing style - use a simple but wellstructured format that gives people ready access to information they might want to have, in just the right amounts.

And in a twist that amused Ev when we got to know each other a little later, this project also took a sharp turn in direction in its first months, when HIRI discovered that our funder had given a grant for a virtually identical project to another researcher at the University of Michigan. To avoid wasting the government's money and turning out two highly overlapping test collections, we used a little interpersonal networking and arranged to "carve up" the territory so that the Michigan project concentrated on published measures, and our project focused on unpublished, often little-known tests that people would have had a difficult time identifying if not for our work. Both the course we chose and the informal way in which we solved a "diffusion problem" were very much in keeping with Ev Rogers's approaches.

The following three decades included, happily, a wealth of collaborations with Everett Rogers. Along the way we worked together in cofounding the Knowledge Utilization Society and participated actively in the Technology Transfer Society, the two professional associations focused specifically on diffusion of innovations. Ev contributed greatly to a series of meetings that helped synthesize the science on this subject that had accumulated by the end of the 1980s, with a particular focus on how this knowledge could be used by federal agencies interested in promoting 
the use of research results. The result was a state-of-the-art monograph published by the National Institute on Drug Abuse (Backer, 1991).

Three years later we worked together, along with Lee Sechrest of the University of Arizona, on an ambitious project to draw together the diffusion strategies that have the most potential for impact in improving the field of health care, working under the aegis of the Agency for Health Care Policy \& Research. Again, a book was the result (Sechrest, Backer, Rogers, Campbell, \& Grady 1994). Both of these books bear the heavy mark of diffusion of innovations theory, as Ev had been advancing it since the original 1962 publication of his book. And both bear the mark of Ev's writing style - they give lots of concrete examples to stimulate the reader's interest as well as to illustrate concepts, use multiple lists of principles to organize complex material, and so forth.

Later Ev did groundbreaking research on how drug abuse and then AIDS got onto the social agenda. And together we looked at how diffusion theory could help us understand how AIDS education programs had moved out into American workplaces and business schools (Backer \& Rogers, 1998; Miller, Backer, \& Rogers, 1997). We also applied these constructs to several other fields, such as substance abuse prevention, in a series of workshops for the Center for Substance Abuse Prevention (also the sponsor of our health communication work together, summarized below).

Ev also had a remarkable gift for bringing together people and institutions that otherwise didn't talk to each other much - he was the best example in the world of the kind of natural networker he studied in his research. After some years of observing how and why he did this, I was able to put these approaches to use on my own, but always drew Ev into the mix as a "partner in crime." For example, we worked together on a unique project under HIRI's umbrella in the mid-1990s. It brought together the federal government and the foundation world around the subject of drug abuse prevention to examine strategies for diffusion of innovations. The National Institute on Drug Abuse and the Ewing M. Kauffman Foundation were the two principal sponsors of this work, which included meetings that bridged these two worlds over a period of several years, exploring possibilities for information sharing and collaboration.

And as was typically the case with any project Ev had a hand in, this "bridging project" also led to publications. Specifically, two books were published. One was a federal monograph, with a chapter by Ev looking at how DARE and other drug abuse prevention programs had been diffused out into the world. This monograph reviewed the knowledge base from the behavioral sciences about diffusion of innovations (Backer, David, \& Soucy, 1995). The other was a small book presenting dissemination strategies that foundations might consider using to promote increased application of results from their grant making (Backer, 1995).

The foundation book went on to have wide use in the field of philanthropy, both here in the United States and in other countries, particularly Canada (where it inspired two Canadian publications) and Australia. That international flavor was particularly appealing to Ev Rogers, who always thought beyond the boundaries of his home country in application of his work. Again, the Ev Rogers style of vivid examples, lists of principles, and striving for ready accessibility of the material all helped to frame these publications.

As I look back on all this work together, which continued through a 2003 "thought paper" on diffusion strategy for a federal agency in the substance abuse prevention field, I can see constantly the influence of these ideas even in writing 
or projects in which Ev Rogers was not a direct participant. Three core strategies, already outlined, that have helped to shape the writing I've done over the yearsuse of lively examples, pithy and well-supported "take home principles" on which people could base practical action, the presentation of science in everyday language - all came directly from my interactions with Ev Rogers, and shape my own writings on diffusion of innovations greatly, these last 35 years.

That working with him also was great fun was just a bonus-his endless enthusiasm and energy, and his wildly creative mind, always searching for new connections and new arenas for exploration. He could get disorganized in the follow-through, because there always were so many things on his plate of professional life, but somehow the important work got done, and in so many different areas. It was always a kind of happy mystery to me how Ev Rogers collaborated with me on several projects at the same time... but I knew he was collaborating on multiple projects with a number of others while he was working with me! In many respects, he turned that sometimes bewildering diversity into a strength, because there always were ideas or opportunities from one project that could be drawn into another.

Thomas Valente. During my doctoral studies Ev and I set up a regular meeting time as I finalized the analysis for my dissertation. In the first meeting I asked Ev some questions regarding early diffusion studies. I was interested in the debate that ensued between sociologists and economists on whether social or economic factors were stronger influences on adoption of farming innovations.

Ev began telling the story of his dissertation study, how it was funded, conducted, and with whom he collaborated. I took copious notes and over the next three meetings Ev expounded on the excitement and dynamics of diffusion study in the mid-1950s in rural sociology. It was fascinating to hear Ev interweave tales of personality and meals with substantive comments on the intellectual contributions of various researchers to the study of diffusion of innovations. And all of these events happened 35 years ago!

After compiling a wad of notes, I said to Ev, "This is really neat historical information, but what does it have to do with my dissertation on mathematical models of diffusion?" Ev chuckled, "Well, "I guess not much." I was a little puzzled; after all, I was planning to defend my dissertation soon.

I said to Ev, "Well, someone should certainly write this stuff up before it disappears." Long silence, raised eyebrows, Ev replied, "Yes, someone should."

I said, "I can type up the notes I have." And I thought I was done with my contribution to the study of the history of diffusion research. I should have known better. Once Ev gets to writing something, and has text in hand, the manuscript cannot escape his thrashing.

After a couple of days I gave Ev a draft of the notes and in a couple of days he returned them to me with copious comments and clarifications throughout in his distinctive scrawl. We began to formulate a story about what this early research meant and how diffusion research conformed to the Kuhnian notion of a paradigm (Kuhn, 1962). Ev suggested we send a draft of our fledgling manuscript to George Beal—his dissertation advisor-who was then living in Hawaii.

George loved the manuscript and invited us to spend a weekend at his home in Hawaii. Ev and I spent a lovely weekend with George and his wife. George recalled the talks he gave on diffusion and had pictures of the felt boards he and Joe Bohlen 
used to give these talks (Beal \& Bohlen, 1955). We tape recorded our conversations and drank Mai Tais on the lanai. Now, this is research I could get used to, I thought.

George's stories whetted our appetite for more. Ev and I plowed through a few more iterations of our paper. I was spending the summer at the University of Michigan and it so happened that the Midwest Rural Sociological Society meeting was being held in Columbus, Ohio, that year. We contacted as many older generation diffusion researchers as we could, making appointments to meet and interview them. Tape recorder in hand, we got more stories from Gerry Klonglan and Milton Coughenour.

A theme that emerged from many interviews was that by the late 1950s, diffusion research had become stale. Diana Crane had formulated this idea in her book Invisible Colleges (1972), and so we combed through her data to see how we could restate her point. Indeed, the ratio of new variables being introduced to the field to the number of publications was quite low (many publications, no new findings or approaches), thus making the field intellectually dull. (My own view is that social network analysis provided an avenue to reinvigorate study of diffusion of innovations, but since most researchers are not trained in the matrix manipulation needed to conduct social network analysis at that time, this path was not taken.)

By the fall of 1991 we had completed our interviews and were nearing a real paper. We sent copies to Diana Crane, Bryce Ryan, and others seeking comments and clarifications. In 1993, the Midwest Rural Sociological Society was holding its meeting in St. Louis, and we submitted a panel in recognition of the 50th anniversary of the landmark Ryan and Gross (1943) study of the diffusion of hybrid corn seed. We had fun at the meeting, but noted that most scholars were interested in collective action and not diffusion, and collective action certainly seemed to be the paradigmatic fad of the 1990s.

Our paper was published in Science Communication (Valente \& Rogers, 1995). It represented years of work conducting personal interviews, analyzing data, writing and rewriting drafts. It was an exciting intellectual journey. I learned more about diffusion research by doing these interviews than any amount of journal reading and data analysis I have done. In the end, this investigation had everything to do with my dissertation and scholarly development, though I couldn't see it at that time. Probably Ev didn't really "see" it either, but he knew it was interesting and he knew this was an activity that would teach me an important lesson about the personal nature of scholarship and the social side of how mathematical models get developed.

It was also classic Rogers: an idea born out of conversation. The kernels thrashed out over multiple drafts of the manuscript. The interviews with knowledgeable people in the field - interviews accompanied with laughter, food, drink, and companionship. Sending the drafts around to get feedback from colleagues, presenting the findings at a meeting. Then, and only then, submitting it for publication. The process is iterative, but fun, and most of all it is a journey of discovery and sometimes enlightenment.

James Dearing. Soon after Ev Rogers's death, I sat next to a man on a Chicagobound flight. He is the medical director for one of the Midwest's premier children's hospitals and is in charge of hundreds of recalcitrant faculty. I told him what I study.

"Really?" he said. "I just read the damndest book about change by some guy named Rogers." It made for a short flight. 
I'm not sure I need comment on Everett Rogers's impact on diffusion of innovation scholarship. That's a bit like asking about Charles Darwin's influence on the study of evolution. For diffusion scholarship, Ev Rogers's impact is perhaps well summarized by asking yourself what the diffusion paradigm would look like if he had never gotten a PhD at Iowa State. Would there be a diffusion paradigm? Without him, the paradigm may never have taken shape, its followers contributing to diverse, not common, cause.

Part of the charge in this article is to assess Ev's impact on us as students and colleagues of his. This task I take up here, hopefully in a way that illuminates characteristics of his, for the insight of others.

Striding through his professional life, Everett Rogers cast a discernable wake about him. I've heard different students of his describe this social effect as a whirlwind, a vortex, a magnetism. The effect was a product of both his own initiative and of other's attention to him. How did he produce this effect, that served him so well for much of his life?

The first time I met Everett Rogers was at Stanford University. I was an undergraduate at a small school, on my way to study abroad in Japan. One of my undergraduate professors - a former student of Ev's - had described some of Dr. Rogers's research and I figured that I had to meet the guy who did all this cool stuff. I put on a suit with wide lapels and a starched shirt and drove from Sacramento to Palo Alto, sweating both from the heat and from rehearsing what I was going to say. Now, I'd never been to Stanford. It can be an intimidating campus to the uninitiated. Center of knowledge and all that. By and by, I find McClatchy Hall, named for the family whose newspaper I'd grown up reading. I stared about the cubicles, properly awed. I found a solitary student. Where, I inquired, could I find the estimable Janet M. Peck Professor of International Communication? The guy looked about and nonchalantly pointed at a rather downtrodden fellow with long beard, Birkenstocks, and Levi jeans accentuated with gigantic holes at the knees. It was Ev Rogers. As we talked, I was further surprised that this unprepossessing fellow was actually interested in what I'd been doing.

Being a star scholar didn't necessitate a coat and tie. Yet as I came to know him, I realized that he knew where the Brooks Brothers stores were in a number of cities.

What the foregoing anecdote does suggest is a keen attention to others, indeed, a sincere personal interest well beyond that expected by social norms. Hundreds of times, I have seen professionals, businesspeople, students, and faculty startled, excited, and privileged at his attention to them. We all know individuals who are self-absorbed. Ev's orientation was the opposite of that. Not that he was selfless. Nor was he without flaws. But with the stranger, the acquaintance, the guest, the foreign visitor, the public health counselor, the destitute on-again off-again drug user, he was predictably attentive and gracious, even consumed. This rote behavior, so atypical for most of us, was a means of learning for him. Perhaps intuitively, Ev understood the social capital advantages of heterophilous relationships. I've never known anyone to have more small-world encounters than Ev Rogers, surely a product of his frequent heterophily.

Writing is, of course, his legacy. He used the process of putting felt-tipped pen to paper as a means of threshing out the chaff, of refining his ideas, and, most bluntly, of thinking. Ev Rogers is an exemplar of E. M. Forster's saying about human learning: "How do I know what I think till I see what I say?" Ev understood better than most of us that we do not know and then commit to write; rather, writing like talking 
is thinking, process not outcome. Creativity, as Max Weber said and as we know, is about bringing intellect to bear on the persistent and emotional pursuit of an idea until you've got it right. That's how Ev Rogers engaged himself on a daily basis.

For Ev, time not spent drafting manuscripts had to be minimized. One of the ways in which he did this was to do two things at once. Students close to him learned by watching that any meeting at which one was expected regardless of topic or importance or size of the group was an opportunity to get other necessary work done. I'm not sure I ever saw him give undivided attention to a topic under discussion. He paid enough attention to make the well-timed insightful comment, often through analogous example, and he was very practiced at offering concise summaries complete with next steps after being silent (he was, after all, doing other work). But the singular fact of many meetings is that they are chock full of wasted time and indecision. He knew it, and because of who he was, he always had piles of papers that were not going to process themselves.

Similarly, at a number of dinners and parties, he'd socialize and then quietly disappear to write. Once at my parents' house, the general cacophony was sufficient enough to drive him into the garage, where he spent a satisfying hour happily writing. My father never forgot Ev's industriousness. A cuba libre followed by a manuscript revision suited Ev to a T.

Writing with Ev, we learned that procrastination and writer's block had no place in the scholarly life. The game, he showed us, was not to figure things out and then write them down. Writing was never the outcome of the scholarly game. Rather, it was the game, played through the back and forth sharing of text, iterations cascading one after the other. Though he most often did it himself, Ev loved having others take the lead in drafting text. That meant you were really playing the game with him, and not merely helping in a lesser capacity.

The same back and forth sharing game was evident in making presentations together, perhaps even heightened. He loved loosely scripted improvisation filled with seat-of-the-pants examples, freely interjected qualifying remarks, and lessons learned. He fed off repartee in front of audiences, and while he had his standard model and consistent points, his usual tone was conversational, and when the situation warranted it, enthusiastic. And the historian in him loved putting his students on the spot, so that others could appreciate our training, which encouraged us to bone up on communication theory, social science history, and the institutionalization of higher education over the last two centuries.

Writing and presenting were key components of the larger scholarly life that Ev modeled for us. We learned by observation and participation to always be curious, to always introduce others to one another, to be gracious, to never dismiss others as unimportant, to always be open to opportunities, and to follow through on promises. His close students, of which I was one, adopted the Rogers head nod, the questioning inflection placed on the negative-affirmative suffix, "no?" and his studious recounting of facts and figures. Our printed notes began to look like his, our briefcases increasingly worn like his. It wasn't conscious imitation. It was contagion.

For graduate students, Ev Rogers modeled modesty, maturity, and a certain cool. Practicing what he knew to be true about opinion leaders, he was highly approachable and ever available. Ev offered graduate students a sort of safe haven, particularly for international students, who found empathy and warmth in him. At the University of Southern California's Annenberg School, prior to his arrival in 
1985 as a chaired professor and director of graduate studies, successive cohorts of doctoral students had wasted away, reduced in number in a rather antiseptic culture. His presence changed that trend, resulting in full cohorts progressing through their programs of study.

Being a star scholar brings with it social burden in the forms of obligation and expectation. Everett Rogers ably carried the diffusion paradigm on broad shoulders for decades after he'd defined it. Not until months before his death did I hear him tell an audience with the S-shaped diffusion curve projected behind him, "Look. I've catalogued these studies up to 5,500. But I'm not doing it anymore. Someone else will have to." Time will tell whether that happens, or not.

\section{Health Communication}

Thomas Valente and Thomas Backer have done research and published widely in the health communication field, with Valente's work in recent years concentrating particularly on issues of evaluating campaigns. Both have collaborated with Ev Rogers in this arena, and here they talk about their work together in this field.

Thomas Valente. Ev Rogers was always generous with his support and assistance, particularly with young scholars. When I was finishing my dissertation, Ev knew the Center for Communication Programs (CCP) at Johns Hopkins University (JHU) had a lot of new data from its multiple international communication projects. He also knew I was particularly interested in empirical estimation of communication effects. He encouraged me to pursue a position with CCP, and when I resisted moving from Southern California he gently convinced me that I was being foolish. Ev had a way of getting you to see things from different angles and from a larger, bigger-picture perspective than you could see on your own.

Over my 9 years at JHU, Ev was a constant collaborator on international research projects. If I was going to see him at a meeting I always planned to have a draft manuscript ready for his crafty hand. I often put manuscripts in the mail to him knowing it would be returned with comments and suggestions within a month. Ev's assistance and encouragement helped us transform a series of case study evaluations into a program of research, which in turn led to many policy-relevant conclusions. More recently, I wrote a book about evaluation of campaigns, which drew together a lot of what I had learned from Ev and our work together (Valente, 2002).

Much of the perspective Ev had about health communication and about diffusion of innovations came from his seeing food, and its production, as a cultural phenomenon. I think in Ev's early life he witnessed the cultural transformation affecting rural life in Iowa. As he experienced it and studied how others experienced it, he no doubt reflected on the forces that defined culture and the mechanisms for its change. This led to an appreciation of communication as a formal area of study. He knew the Shannon and Weaver (1949) mathematical theory of communication book and knew communication was emerging as a new field of study. Although he elected to stay at Iowa State University and complete his $\mathrm{PhD}$ in rural sociology, Ev was always certain that communication was the key to understanding social change. And it wasn't long before he realized that communication was the key to improving health and the quality of life for the world's disadvantaged and underserved.

Food was a particular joy for Ev in his personal life, too. First and foremost he was a gardener, and could talk endlessly about how his crops were doing any given 
year. And he could fondly recall gardens he'd put in at any of his many residences. On the steep slope of his Hollywood Hills home (where he lived while teaching at the University of Southern California), he planted tomatoes, cucumbers, squash, and beans, and would regularly bring extras to school. Ev liked to make things grow, and I always felt gardening was a metaphor for his life: He was nurturing and not beyond pulling weeds that had to be pulled. He paid attention to what soil was right for which plants and which years, and judiciously used fertilizers.

Food was also important as a means to understand cultures. Ev was extremely fascinated with others and with their cultures. He wanted to know a person's history in part to learn about their world. He felt that food was an important component to culture and would have potluck celebrations to end his classes and relished (pun intended) the variety of dishes people would bring. He'd ask about each one, how it was made, and where it came from.

He also saw food as a social lubricant, a good way to get a party going. I can still see him presiding over a kitchen filled with colleagues all hustling about making our dishes and chatting about everything under the sun. His enthusiasm and appreciation for each and every dish was genuine. He loved dessert, particularly cobblers with ice cream. Every meal I had with Ev (and there were quite a few) finished with a little something sweet. He knew how to live.

There was scholarship in all this fun. Learning about different cultures, meeting people from different places, and forming a supportive and caring community helped scholars reach their potential. The first entertainment-education conference was held at Annenberg in 1989, and Ev invited some 70 participants to his house for dinner. It was a raucous celebration, but it created an identifiable moment in the history of entertainment-education scholarship. Everyone who was there marks it as the time when entertainment-education became a cohesive field of scholarship.

Ev's approach was to invite everyone and let the mixing begin. He was terrific at introducing people and getting a conversation going. If a joint project came out of the discussions, he was quick to get the ball rolling - and either take the lead or cede power, whichever was best. He was a terrific collaborator, but he did something that few people can do-he eschewed organizational politics and gossip. He was too busy to worry over who was doing what to whom, but instead focused on writing, presenting, teaching, and sharing.

He taught us all the value of review and edit. All of his students heard the story of how he rewrote his first publication 19 times before he was ready to submit it. And all of his students wondered at some point or another whether the draft we were working on would ever see the light of day. But we were learning a valuable lesson that writing is about editing and rereading and reconsidering the text we were massaging. Just when you thought it was done, Ev suddenly thought of someone else's perspective that should be included or consulted before the paper could go out for review.

He taught us that sharing drafts was a way to exchange ideas. Most importantly, he taught us to share ideas and to seek out colleagues with similar interests. For Ev, scholarship was simultaneously a monastic solitary endeavor and an intensely social and engaging process. It was iterative to a fault, but he never wanted his work or that of his students to be sloppy or unprepared. He had respect for the work we did and in the end that generated a considerable amount of respect for the work he did.

Part of the iterative writing process was designed to whittle away at a topic until one found the kernel of the issue. Ev was particularly adept at pruning away the 
clutter to find the heart of a scientific problem. He could synthesize dozens of studies because he knew how to digest the papers in a way that uncovered the commonality inherent in different approaches. This again was his ability to find commonality in heterogeneous places, I suppose from his long-standing interest in exploring different cultures.

Thomas Backer. At the end of the 1980s, Ev Rogers and I began working on a 3year research project that led to two textbooks on health communication campaigns (Backer \& Rogers, 1993; Backer, Rogers, \& Sopory, 1992). These books had the overall goal of addressing three aspects of health communication campaigns that had not been previously dealt with much in the literature on this subject: (1) development of generalizations to answer the basic question, "What works?" now that there were both successful campaigns and research on their impact to draw from, that hadn't existed before; (2) study of the characteristics, experiences, philosophies, and creative styles of the campaign designers who are quite influential in how campaigns develop and which ones succeed; and (3) study of the characteristics of the organizations involved in these complex campaigns, which depend upon a complex interorganizational network if they are to succeed.

These were topics that personally interested us, and which certainly reflected the "Ev Rogers writing style" - and now mine, too. But we also saw our work on these aspects of health communication campaigns as a way to advance the field, both through setting some initial practice standards that might be useful to others, and through improving the understanding of the two most important actors in campaigns (neither of which previously had been studied much).

In the first book, Designing Health Communication Campaigns, 29 world leaders in health communication were interviewed (a thorough literature review also was done) to form the basis for generalizations about health communication campaigns and their designers. The interviews were conducted not by Ev or me but by a doctoral student, Pradeep Sopory, a new scholar in the field who has gone on to his own distinguished career. This was not just a way to provide a uniquely valuable opportunity to a graduate student but also as a way of bringing a fresh point of view to the material. This also was an approach to research and writing I've learned from $\mathrm{Ev}$, and which has served me well in a number of subsequent projects: the value of a fresh eye, particularly for qualitative material.

In the second book, Organizational Aspects of Health Communication Campaigns, interorganizational networks that each of six major campaigns (like the Partnership for a Drug Free America) had developed were studied in an unusual way. We looked to a strategy that would promote the "collision of ideas," by bringing together management scientists and communication campaign experts. This worked out well and provided more of a latticework for understanding the implications of all that we learned about health communication campaigns over a number of years.

We've been glad to see the books get some use over a period of years, including adoption as texts for health communication courses in major universities. As Professor Doe Mayer of the USC Film/TV School, put it,

These books have added a critical dimension to the course on designing campaigns I co-teach with Peter Clarke in the USC Annenberg School for Communication. They provide principles and direction, and help 
students understand in a more practical way how to design and evaluate campaigns. I think they do just what Ev and his co-writers wanted them to do-they help students apply information without formularizing it. That was one of Ev's great qualities. He was a scientist who understood the constant need to re-evaluate and stay responsive. He was amazingly open to new ideas and creative thinking. What a great gift that was to both his students and his colleagues.

\section{Entertainment-Education}

Entertainment-Education (E-E) is growing area of research and practice in health communication. It involves the strategic use of entertainment media to address a wide variety of social issues, including HIV/AIDS prevention, small family size, and gender inequality. Arvind Singhal is a leading researcher in this area, and also a student and long-time collaborator of Ev Rogers.

Arvind Singhal. I first talked to Ev Rogers on a cold winter evening in February 1985. I was a second-year MA student in Radio-TV-Film at Bowling Green State University. Everett M. Rogers was the Janet M. Peck Professor of International Communication at Stanford University, and recently had accepted an appointment as Walter H. Annenberg Professor of Communications at the University of Southern California's (USC's) Annenberg School. Although the temperature outside my frosted window was 20 degrees below freezing, my palms were sweaty. I nervously dialed the telephone to talk to the "distinguished" professor:

"Good evening, Professor ... umm ....Dr. Rogers, I am Arvind Singhal." He replied, "Hi, Hi, Arvind, I have heard a lot about you. I think I already know you.... And please call me Ev." He instantly put me at ease. We talked for 35 minutes.

Halfway through the conversation, I asked him my carefully rehearsed question, slowly reading from my notes: "Dr. Rogers, I need some advice. I have been admitted with a fellowship to both Stanford University and to the USC Annenberg School's doctoral program ....I am torn.... What should I do?"

There was a pause. Ev cleared his throat and noted: "Arvind, remember, whatever you decide, you will not be making a right or wrong decision .... just a different one."

That phone call was my introduction to Ev Rogers. He showed an interest in me. He validated me. He helped me in making up my mind. These gestures - genuinely motivated and effortlessly executed - were Ev's personal signature. After I put down the phone, I signed the Annenberg School contract, and later that Fall joined Jim Dearing and eight others in our doctoral cohort at USC.

It was the beginning of a long association with Ev Rogers. "We have had long innings together," he noted, when I saw him last in September 2004, 4 weeks before he passed away. In simple counts (Ev liked simple "meta" counts), our two decades of association took us to more than 20 countries, and yielded five coauthored books and some four dozen journal articles, book chapters, and grant proposals. "It's been an enjoyable ride," he said when we bid goodbye. 
Ev Rogers was a quintessential storyteller. He had a story for every occasion, and it did not matter if you had heard it previously; they got better with each iteration. Stories, vignettes, and examples were integral to his teaching, writing, and mentoring. He believed in E-E and was its consummate practitioner-much before the term E-E was officially coined.

In Fall 1985, in his Communication and National Development class at USC, Ev showed a 3-minute videotape of the popular Indian soap opera, Hum Log (We People), illustrating its purposive combination of entertainment and education as a means of promoting social change. A few months previously, in India, I had witnessed first-hand the effects of Hum Log on Indian audiences, including on my 72-year-old grandmother, who watched each episode without fail. A hush fell in our living room when Ashok Kumar, a highly respected Indian movie actor (akin to Burt Lancaster), delivered the 30-second epilogue at the conclusion of each episode, summarizing the intended social message, raising rhetorical questions for the viewers to ponder, and providing viewers with guides to action. Animated discussions about the plot of Hum Log and the tribulations of its characters were common in social gatherings I attended in New Delhi. A Hum Log fever was palpably raging in India.

Ev first became aware of E-E television soap operas in 1975, when a Mexican television official doing graduate work at Stanford University told him about Simplemente Maria, a 1969-1971 Peruvian television soap opera, which influenced its viewers to enroll in literacy and sewing classes, modeling their behaviors after María, its protagonist (Singhal, Obregon, \& Rogers, 1994). Through this Mexican student, Ev also learned of Miguel Sabido, a producer-director-writer at Televisa, the Mexican commercial network, who had implemented the unique idea of combining entertainment with education in telenovelas. Only in-house evaluation research on the effects of Sabido's telenovelas had been conducted in Mexico, and these studies had not found their way into the mainstream of communication science literature. When the Mexican soap opera experience was transferred to India in the form of Hum Log in 1984-1985, however, it presented a unique opportunity for scholarly research.

When I launched into a 10-minute testimonial on Hum Log in Ev's class that Fall of 1985, his eyes lit up, his voice hit a high note, and he rubbed his hands in glee. We chatted about Hum Log during the class break, and in his Mercedes as he dropped me at my apartment. We chatted some more in the parking lot. As he drove away, he winked and said, "Arvind, wouldn't it be fun to study the effects of Hum Log in India?"

Ev had an uncanny ability to smell exciting research topics and get them underway without much fuss. His enthusiasm was infectious. Or, as others have noted, contagious.

At the end of each semester, Annenberg School doctoral students participated in a "semester review." Each student discussed his or her semester's performance in the presence of the entire Annenberg School faculty (a rather stressful event), and future directions for the student's study and research were charted. In my December 1985 semester review, the late Professor Robert William (Bill) Hodge suggested that I apply to the Rockefeller Foundation's program on the status of women and fertility for a research grant to study the effects of Hum Log (which was designed with the purpose of promoting gender equality and small family size).

As a first-year doctoral student, I thought Dr. Hodge's idea was far-fetched. Ev, naturally, thought differently. He loved the idea of raising research dollars for exciting research initiatives, and was a pro at crafting research grant proposals. Except, this 
time, he wanted me to take the lead in drafting the Rockefeller proposal. "Me?????" I looked at him quizzically. "There's not much to it," he said with assurance.

The research grant proposal went through the proverbial 19 rounds of Ev Rogers' iterations, with marked-up purple-pen edits showing up in my mailbox almost every morning. My "writing”, education with Ev Rogers was well underway.

Six months later, Dr. Mary Kritz, the officer in charge of the Rockefeller Program called Ev from New York and said we had the funds to conduct an evaluation of Hum Log.

Such were the beginnings, some 19 years ago, of our collaborative journey on the path of E-E. With colleagues at USC, University of New Mexico, Ohio University, and other institutions, Ev and I studied E-E initiatives in India, Peru, Mexico, China, Tanzania, South Africa, Thailand, Kenya, and Brazil. In 1997, 7 years after I finished my doctoral dissertation on E-E, and after two highly effective E-E conferences at USC (in 1989) and at Ohio University (in 1997), we sensed that the time was ripe for a book on the topic. By this time, scores of E-E initiatives were underway in dozens of countries. A body of research literature on E-E was available, and growing.

On a bumpy bus ride in Costa Rica, while driving toward San Jose, the capital city, Ev pulled out his Stabilo Sensor purple pen and his black-leather jacketed "Memogenda" and initiated our book's outline. He nodded off at least half-a-dozen times (we were returning from an exhausting all-day tour of a coffee plantation and the Costa Rican rainforest), but the pen picked up from exactly where it had trailed off when the bus hit a bump (many believed that Ev wrote in his sleep too!).

A few months later, at the International Communication Association 1998 convention in Jerusalem, we met with Linda Bathgate, the Communication Editor for Lawrence Erlbaum Associates (LEA), and a contract was signed. In mid-1999, Entertainment-Education: A Communication Strategy for Social Change (Singhal \& Rogers, 1999) was published. A year later, it was honored with National Communication Association's Distinguished Scholarly Book Award in Applied Communication and was widely adopted as a text in communication and public health courses at various U.S. and overseas universities.

In 2002, with the encouragement of Professor Michael Cody, the then-editor of Communication Theory, Ev and I edited a special issue of the journal on E-E. There were several excellent submissions, but we could accommodate only six articles. So, the idea of an edited volume on E-E was broached, once again, with Linda Bathgate at LEA. This 22-chapter volume-representing multiple E-E projects from across the world and signifying multiple theoretic and methodological approaches to E-E - was published in 2004 (Singhal, Cody, Rogers, \& Sabido, 2004).

Ev Rogers, raised on an Iowa farm in the 1930s, knew how to plant seeds, till the land, and harvest a crop. Once, in 2000, at a convention in Phoenix, I overheard Ev say, "All my life I have tried to plant little acorns, and then watch them grow into trees."

The kernel of the E-E idea, planted by Ev in a graduate seminar at USC in 1985, is shaping into a robust tree.

\section{References}

Backer, T. E. (1991). Drug abuse technology transfer, Rockville, MD: National Institute on Drug Abuse.

Backer, T. E. (1995). Dissemination and utilization strategies for foundations: Adding value to grantmaking, Kansas City, MO: Ewing M. Kauffman Foundation. 
Backer, T. E., David, S. L., \& Soucy, G. (Eds). (1995). Reviewing the behavioral science knowledge base on technology transfer, Rockville, MD: National Institute on Drug Abuse.

Backer, T. E. \& Rogers, E. M. (Eds.) (1993). Organizational aspects of health communication campaigns: What works? Newbury Park, CA: Sage Publications.

Backer, T. E. \& Rogers, E. M. (1998). Diffusion of the business responds to AIDS program among U.S. companies. Journal of Health Communication, 3, 17-28.

Backer, T. E., Rogers, E. M., \& Sopory, P. (1992). Designing health communication campaigns: What works? Newbury Park, CA: Sage Publications.

Beal, G. M. \& Bohlen, J. M. (1955). How farm people accept new ideas (Report 15). Ames, IA: Cooperative Extension Service.

Crane, D. (1972). The invisible colleges: Diffusion of knowledge in scientific communities, Chicago, IL: University of Chicago Press.

Kuhn, T. (1962). The structure of scientific revolutions, Chicago, IL: University of Chicago Press.

Miller, A. N., Backer, T. E., \& Rogers, E. M. (1997). Diffusion of workplace AIDS education programs among American business and business schools. Business Horizons, JulyAugust, 78-86.

Ryan, R. \& Gross, N. (1943). The diffusion of hybrid seed corn in two Iowa communities. Rural Sociology, 8(1), 15-24.

Sechrest, L., Backer, T. E., Rogers, E. M., Campbell, T. F., \& Grady, M. L. (Eds.). (1994). Effective dissemination of clinical and health information, Rockville, MD: Agency for Health Care Policy and Research.

Shannon, C. E. \& Weaver, W. (1949). The mathematical theory of communication, Urbana: University of Illinois Press.

Singhal, A., Cody, M. J., Rogers, E. M., \& Sabido, M. (Eds.). (2004). Entertainment-education and social change: History, research, and practice, Mahwah, NJ: Lawrence Erlbaum Associates.

Singhal, A., Obregon, R., \& Rogers, E. M. (1994). Reconstructing the story of "Simplemente María," the most popular telenovela in Latin America of all time. Gazette, 54, 1-15.

Singhal, A. \& Rogers, E. M. (1999). Entertainment-education: A communication strategy for social change, Mahwah, NJ: Lawrence Erlbaum Associates.

Valente, T. W. (2002). Evaluating health promotion programs, London: Oxford University Press.

Valente, T. W. \& Rogers, E. M. (1995). The origins and development of the diffusion of innovations paradigm as an example of scientific growth. Science Communication, 16(3), 238-269. 